\title{
Building and Environment
}

\section{Highlights}

- Strong mismatch between electricity demand and production in net zero-energy dwelling.

- Significant potential for short-term peak load shifting using structural thermal mass.

- Influence of thermal properties of dwelling on demand-side management is evaluated.

- Floor heating system shows higher demand-side management potential than radiators.

- Model-based control able to reduce storage losses and guarantee thermal comfort. 


\title{
Potential of structural thermal mass for demand-side management in dwellings
}

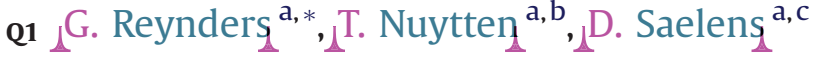 \\ ${ }^{a}$ Energyville, Dennenstraat 7, BE-3600 Genk, Belgium \\ ${ }^{\mathrm{b}}$ VITO, Unit Energy Technology, Boeretang 200, BE-2400 Mol, Belgium \\ c Building Physics Section KU Leuven, Kasteelpark Arenberg 40 - Box 2447, BE-3001 Heverlee, Belgium
}

\section{A R T I C L E I N F O}

\section{Article history:}

Received 5 December 2012

Received in revised form

25 February 2013

Accepted 14 March 2013

\section{Keywords:}

Building energy simulations

Thermal storage

Demand-side management

Renewable energy

\begin{abstract}
A B S T R A C T
In order to avoid grid instability and decreasing production efficiencies of large power plants due to a widespread integration of renewable electricity production, demand-side management (DSM) is proposed as a solution to overcome the possible mismatch between demand and supply. This research evaluates the potential to improve the balance between the electricity use for heating and local electricity production of a nearly zero energy building (nZEB), by active use of structural thermal storage capacity of the building.

To quantify the DSM potential of structural thermal storage, the cover factors and peak electricity demand of a single family dwelling equipped with a photovoltaic (PV) system are chosen. Detailed representations of the PV system and the dwelling itself, heated by an air-water heat pump, are implemented in the modeling environment of Modelica and simulated for the heating-dominated climate of Belgium. The influence of the insulation level and the embedded thermal mass of the construction on the DSM potential is evaluated. The impact of the heat emission system is estimated by comparing a floor heating system with a radiator emission system.

Results show that although the influence on the cover factors is limited, the use of the structural storage capacity for demand-side management shows strong potential to shift the peak electricity use for heating to off-peak hours. Furthermore, it is shown that not only the availability of the thermal mass, but also the interaction between the heating system and the thermal mass is of significant importance.
\end{abstract}

(c) 2013 Published by Elsevier Ltd.

\section{Introduction}

Large-scale integration of decentralized electricity production from renewable energy sources is often suggested as a key technology to counter fuel poverty and climate change. Statistics show how the potential production from renewable sources may outgrow the demand by far [1,2]. However, an important bottleneck lies, amongst others, within the strong intermittent characteristics of electricity production from solar or wind energy. Because of the stochastic nature of both the electricity demand and renewable electricity production, a possible mismatch may occur between demand and supply [3-5].

Commonly the electricity grid is used as a virtual storage to overcome the mismatch between local electricity production and demand [6,7]. With an increasing penetration of renewables this

\footnotetext{
* Corresponding author. Tel.: +32 (0)16 321080.

E-mail address: glenn.reynders@bwk.kuleuven.be (G. Reynders).
}

approach will no longer be sustainable, resulting in grid instability and decreasing efficiencies of large power plants [8-10]. Largescale integration of renewables therefore requires the development of intelligent electricity networks, so-called Smart Grids [11]. Smart Grids integrate real-time communication [12] between actuators on both demand and supply side, that enables demand-side management (DSM) [13] and the use of storage technologies [14$16]$ in order to optimize the use of renewable energy sources [17].

Within the context of Smart Grids, buildings can play an important role. The energy demand of the building stock is estimated at $38 \%$ of total energy use worldwide and therefore shows a large potential for energy savings and demand-side management $[18,19]$. To activate this demand-side management potential, the embedded thermal mass of a building may be actively used as structural thermal storage capacity. Therefore intelligent control strategies can be used to optimize the use of thermal storage in buildings by taking into account the thermal characteristics of the building and time-of-use energy prices provided by smart meters $[20,21]$. Simulation-based and experimental results show that a http://dx.doi.org/10.1016/j.buildenv.2013.03.010 


\section{Nomenclature}

$\dot{m}_{w} \quad$ mass flow rate $[\mathrm{kg} / \mathrm{s}]$

$\gamma_{d} \quad$ Demand cover factor [-]

$\gamma_{s} \quad$ Supply cover factor $[-]$

$c_{w} \quad$ Specific heat capacity of water $[\mathrm{J} /(\mathrm{kg} . \mathrm{K})]$

$C_{\text {eff }} \quad$ Effective thermal storage capacity $[\mathrm{J} / \mathrm{K}]$

E Electricity use [kWh]

$P \quad$ Electricity demand [W]

$P_{\text {dom,net }}$ Net domestic electricity demand [W]

$P_{\text {dom }} \quad$ Domestic electricity demand [W]

$P_{\max } \quad$ Upper threshold for net domestic demand [W]

$P_{\min } \quad$ Lower threshold for net domestic demand [W]

$P_{\mathrm{PV}} \quad$ PV production [W]

$Q \quad$ Heat demand [W]

$Q_{c} \quad$ Convective heat [W]

$\mathrm{Q}_{\mathrm{r}} \quad$ Radiative heat [W]

$Q_{\text {nom }} \quad$ Nominal thermal power [W]

$Q_{\text {pred }} \quad$ Predicted heat demand [W]

$T_{w} \quad$ Water temperature $\left[{ }^{\circ} \mathrm{C}\right]$

\author{
$T_{c, i} \quad$ Air temperature of zone i [ $\left.{ }^{\circ} \mathrm{C}\right]$ \\ $T_{\max } \quad$ Maximal comfort temperature $\left[{ }^{\circ} \mathrm{C}\right]$ \\ $T_{\min } \quad$ Minimal comfort temperature $\left[{ }^{\circ} \mathrm{C}\right]$ \\ $T_{\mathrm{op}} \quad$ Operative temperature $\left[{ }^{\circ} \mathrm{C}\right]$ \\ $T_{\text {set }} \quad$ Setpoint temperature for heating $\left[{ }^{\circ} \mathrm{C}\right]$ \\ WTD Weighted temperature deviations [Kh] \\ COP Coefficient of performance \\ DSM Demand-side management \\ HP Heat pump \\ HW Heavy-weight \\ IDEAS Integrated district energy assessment simulations \\ LW Light-weight \\ MPC Model predictive control \\ noQpred Non-predictive control \\ nZEB Nearly zero energy building \\ PV Photo-voltaic \\ Qpred $_{A} \quad$ Predictive control A \\ Qpred $_{B} \quad$ Predictive control B \\ Ref Reference thermostatic control
}

model predictive control strategy (MPC) that takes into account both the structural storage capacity of the building and the active thermal storage capacity may result in energy cost savings of $26 \%$ up to $40 \%$ [22,23], while maintaining or even improving thermal comfort. These savings mostly result from the free cooling potential (eg. through night ventilation) [24], a higher contribution of solar and internal gains for passive heating [25] and the price differences between peak to off-peak periods. Nonetheless, it is found that savings strongly depend on the coupling of the building to the outdoor environment, since the activation of the structural storage gives rise to increased conduction losses.

While these studies mostly focus on commercial buildings in cooling conditions, this work analyses DSM opportunities using the structural thermal mass in a heat pump (HP) equipped dwelling for the heating-dominated climate of Uccle (Belgium). Thereby the activation of the structural storage capacity demands for a dynamic control of the indoor temperature. In a Smart Grid context, such dynamic control strategy would preheat the building and activate the storage capacity by increasing the indoor temperature setpoint when the time-of-use electricity price is low. Alternatively, the heating setpoint could be lowered when the electricity price peaks. Consequently the thermal mass releases the stored energy thereby reducing the electricity demand of the HP.

Evidently, thermal comfort plays an important role in the potential of structural storage as it imposes limits to the allowable temperature fluctuations when the building is occupied. In literature, two general approaches are found to take into account the thermal comfort limits into DSM control strategies. A first approach introduces thermal comfort into the cost function that is optimized to calculate the temperature setpoints $[25,26]$. As such the cost for deviations from the comfort temperature should be defined and evaluated against the energy cost for heating. Specifying the cost for comfort violations is proven difficult due to the subjective nature of thermal comfort sensation [27]. Therefore the second approach uses thermal comfort criteria to impose boundary conditions to the optimization problem. The level of allowed temperature fluctuations is then based on thermal comfort standards. Commonly thermal comfort criteria are specified in steady state using the PMV-PPD method introduced by Fanger [28] and employed in the ISO 7730 standard [29]. However, Humphreys and Nicol [30] show that due to the flexibility of users in residential buildings, steady state comfort models are no longer valid. Over the last decades the use of adaptive thermal comfort criteria has been suggested in residential buildings to account for the wide range of possibilities to adapt to the thermal environment [31,32]. However, it could be argued that the use of optimal control strategies limits the freedom of the users and thus violates the requirements for adaptive comfort criteria. Therefore a fixed comfort band is used for the simulations as explained in section 2.

In addition to thermal comfort, the thermal performance of the building envelope is expected to influence the potential of structural storage. Since the activation of the thermal mass demands for temperature fluctuations, the use of structural storage might result in increased transmission and ventilation losses [33]. As such it could be expected that the efficiency of the structural storage is higher for well insulated buildings. Additionally, advanced control strategies, such as MPC, can be implemented to minimize the additional losses by optimizing the trajectory of the heating setpoint [34]. Therefore MPC uses reduced order building models to predict the future heat demand of the dwelling based on predictions of the future climate data and occupant behavior. The efficiency of these control strategies strongly depends on the accuracy of these reduced order models [35].

Finally, literature shows that the DSM potential is function of the availability of thermal mass [36]. Thereby the availability of thermal mass is not only function of the material properties at the interior surfaces. Also the geometry of the building, the distribution of the thermal mass and interaction between the heating or cooling systems and the thermal mass play a role in the potential of structural thermal storage [37-41].

In order to assess the potential of structural thermal storage for demand-side management, building energy simulations have been carried out for a single family house equipped with a PV system for local electricity production and a HP system for space heating. The simulations are used to quantify the influence of activating the structural storage capacity of a dwelling on the balance between the electricity demand for heating and the local electricity production from a PV system. The influence of the construction type is taken into account by specifying 6 construction types, i.e. 3 insulation levels for both a heavy-weight and light-weight construction. A description of the building model is given in section 2.1.

Both a floor heating system and radiator emission system are implemented to analyze the interaction between the heat emission system and the structural thermal energy storage, as described in 
section 2.3. Three different DSM control strategies, described in section 2.4, are implemented to activate the thermal mass and compared against the reference thermostatic control.

A total of 48 cases are simulated to assess the potential of structural thermal storage in a single family nZEB. Subsequently the potential is quantified by the ability of a DSM control strategy to improve the cover factor of the PV system and to shift the peak electricity demand of the HP by using structural thermal storage. The evaluation criteria are described in section 2.5.

The results for DSM control strategies (section 3.3) are shown and compared against the results for the buildings equipped with the reference thermostatic control (section 3.2) and against the results for domestic electricity use only (section 3.1). The influence of the thermal properties of the building is discussed in section 3.3.2. Finally, the most important results and the potential impact of DSM using the structural storage in the context of Smart Grids is discussed in section 4 .

\section{Methodology}

\subsection{Building model}

A single family house is modeled using the IDEAS library, developed at KU Leuven. The IDEAS library is implemented in Modelica and enables integrated simulations of buildings, thermal systems and the electricity grid, as described in Baetens et al. [3].

The dwelling, an example of a typical Belgian detached single family house [42], has a total floor area of $140 \mathrm{~m}^{2}$ and consists of 10 zones that are implemented individually into the simulation model (Fig. 1). On the ground floor, (1) the living room, (2) kitchen, (3) study room, (4) toilet and (6) utility room are located. Three bedrooms $(7,8,9)$ and the bathroom (10) are located on the first floor. The circulation area (5) covers both floors. The building envelope has a total surface area of $365 \mathrm{~m}^{2}$, a volume of $451 \mathrm{~m}^{3}$ and a compactness of $1.24 \mathrm{~m}$. Both a heavy-weight (HW) and lightweight (LW) variant for the dwelling have been implemented. The thermal properties of the envelope components are summarized in Table 1 . The insulation thickness of these components has been varied, resulting in three insulation levels with an average heat transmission coefficient for the building of $0.19 \mathrm{~W} /\left(\mathrm{m}^{2} \mathrm{~K}\right)$, $0.37 \mathrm{~W} /\left(\mathrm{m}^{2} \mathrm{~K}\right)$ and $0.56 \mathrm{~W} /\left(\mathrm{m}^{2} \mathrm{~K}\right)$. These insulation levels will be referred to as the K20, K40 and K60 respectively.

A balanced ventilation system with heat recovery is implemented. The air flow rates are based on the Belgian national standard NBN50-001 [43] and result in a total hygienic ventilation rate
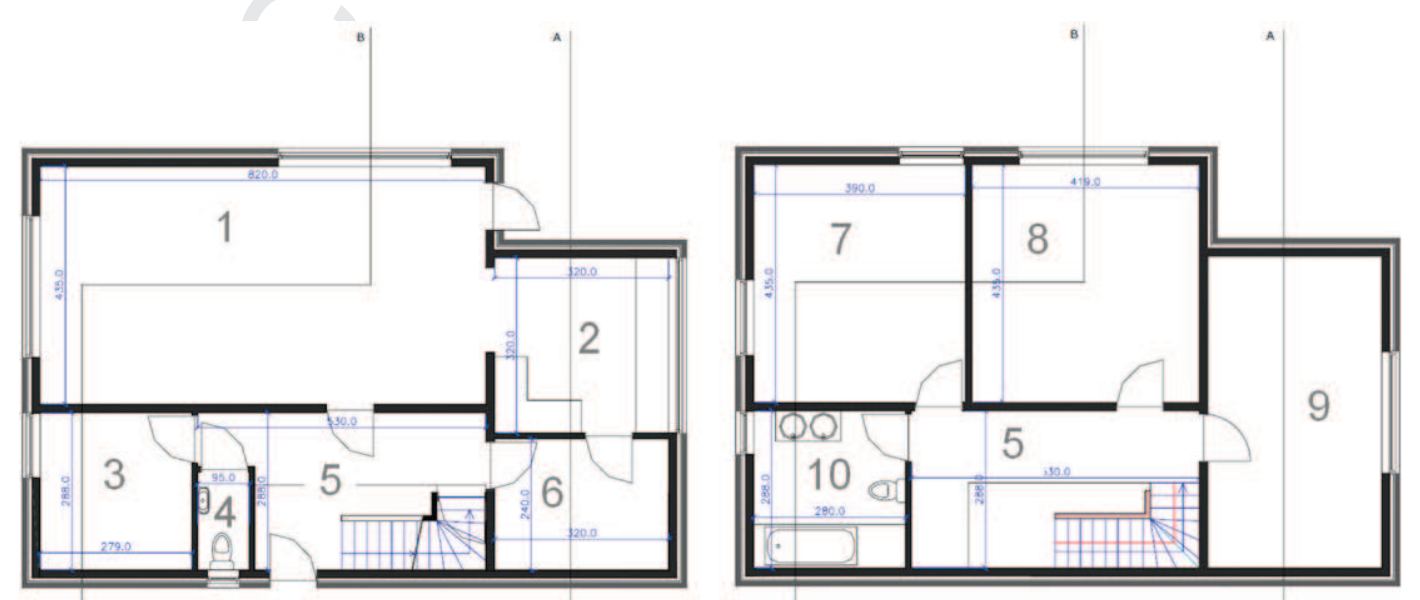

Fig. 1. Floor plan of the ground floor (left) and first floor (right) of the detached building.
Table 1

U-values and thermal capacity of the construction components for the heavy-weight and light-weight building for the designed K20, K40 and K60 insulations levels.

\begin{tabular}{lllllll} 
Component & \multicolumn{2}{l}{$\mathrm{U}$-value $\left[\mathrm{W} /\left(\mathrm{m}^{2} \cdot \mathrm{K}\right)\right]$} & & \multicolumn{2}{l}{ Capacity $\left[\mathrm{kJ} /\left(\mathrm{m}^{2} . \mathrm{K}\right)\right]$} \\
\cline { 2 - 3 } & $\mathrm{K} 20$ & $\mathrm{~K} 40$ & $\mathrm{~K} 60$ & & Light-weight & Heavy-weight \\
\hline Ground floor & 0.094 & 0.192 & 0.226 & & $413-431$ & $413-431$ \\
Roof & 0.112 & 0.267 & 0.614 & & $17-110$ & $17-110$ \\
Exterior wall & 0.127 & 0.387 & 0.548 & & $130-204$ & $214-223$ \\
Internal wall & 1.247 & 1.247 & 1.247 & & 22 & 116 \\
Internal floor & 2.214 & 2.214 & 2.214 & 421 & 421 \\
Window & 1.1 & 1.1 & 1.1 & $/$ & $/$ \\
\hline
\end{tabular}

of $518 \mathrm{~m}^{3} / \mathrm{h}$ for the dwelling. The heat recovery system is assumed to have a constant efficiency of $84 \%$. The application of this system demands for an airtight envelope to minimize infiltration losses. For this dwelling the infiltration rate is assumed to be $10.8 \mathrm{~m}^{3} / \mathrm{h}$.

External shading device is implemented to reduce overheating and improve thermal comfort during summer. The shading control is based on the indoor temperature in an attempt to simulate manual control. The shading device closes when the indoor temperature rises above a certain threshold as specified in Table 2. To prevent instable behavior, a hysteresis loop of $2{ }^{\circ} \mathrm{C}$ is used for the shading control. When closed, the shading device blocks the direct solar radiation and reduces the diffuse solar radiation that passes through the window by $76 \%$. The g-value of the glazing is 0.598 .

\subsection{Photovoltaic system}

The implementation of the PV system in Modelica is described in [44]. The output of the PV system is simulated using 15-min radiance data obtained with Meteonorm v6.1 [45] for the moderate climate of Uccle (Belgium). The Skatveith-Olseth model is used to determine the diffuse radiation [45]. For an ideal inclination of $34^{\circ}$ with south orientation, an annual electricity production of $889 \mathrm{kWh} / \mathrm{kWp}$ is found. Dimensioning of the PV systems is performed for each individual case to achieve a predicted level of onsite net zero energy. The nZEB criterion is defined according to the Net Zero Site Energy criterion stating that 'a net zero-energybuilding produces at least as much energy as it uses in a year, when accounted for at the site' [6].

\subsection{Heating system}

The central hydronic heating system consists of an air-to-water heat pump for the heat production combined with low 
Table 2

User schedule.

\begin{tabular}{|c|c|c|c|c|c|}
\hline Rooms & $\begin{array}{l}\text { Temperature } \\
\text { set-point }\end{array}$ & $\begin{array}{l}\text { Occupancy } \\
\text { weekdays }\end{array}$ & $\begin{array}{l}\text { Occupancy } \\
\text { weekends }\end{array}$ & $\begin{array}{l}\text { Shading } \\
T_{\text {close }}\end{array}$ & $\begin{array}{l}\text { Shading } \\
T_{\text {open }}\end{array}$ \\
\hline $\begin{array}{l}\text { Living room, } \\
\text { kitchen, } \\
\text { office room }\end{array}$ & $22.5^{\circ} \mathrm{C}$ & $\begin{array}{l}\text { 07:00-09:00 } \\
\text { 12:00-13:00 } \\
\text { 17:00-22:00 }\end{array}$ & $08: 00-23: 00$ & $25^{\circ} \mathrm{C}$ & $23{ }^{\circ} \mathrm{C}$ \\
\hline Bathroom & $24^{\circ} \mathrm{C}$ & $\begin{array}{l}07: 00-09: 00 \\
18: 00-20: 00\end{array}$ & $\begin{array}{l}08: 00-10: 00 \\
17: 00-21: 00\end{array}$ & $27^{\circ} \mathrm{C}$ & $25^{\circ} \mathrm{C}$ \\
\hline Bedrooms & $18^{\circ} \mathrm{C}$ & $20: 00-08: 00$ & $20: 00-09: 00$ & $22{ }^{\circ} \mathrm{C}$ & $19{ }^{\circ} \mathrm{C}$ \\
\hline
\end{tabular}

temperature heat emission systems. Production of domestic hot water has not been taken into account. The heating system is designed according to EN12831 [46] with an outdoor design temperature of $-8{ }^{\circ} \mathrm{C}$. The implementation of the air-to-water heat pump in Modelica is described in section 2.3.1. The design and implementation of both the low temperature radiators as well as the floor heating system is described in section 2.3.2.

\subsubsection{Heat production}

An air-to-water heat pump (HP) is implemented for heat production. The HP model relies on an interpolation of manufacturer data, which specifies the heating power $(Q)$ and electricity demand $(P)$ as a function of the condenser temperature and the evaporator temperature. The nominal condenser temperature is equal to the nominal supply temperature for the heat emission system and is set to $45^{\circ} \mathrm{C}$. An ideal heat exchange between condenser and water is assumed.

The design HP power $\left(Q_{\text {Nom }}\right)$ for the different insulation levels and heat emission systems is summarized in Table 3. Modulation is allowed to match the HP output to the heat demand of the building, with a part load ratio varying between $30 \%$ and $100 \%$ of the design power. Note that this implies that the HP is inactive when the heat demand in the building does not exceed $30 \%$ of the nominal demand. During mid-season this may introduce comfort problems and important cycling behavior of the HP. In practice, a water storage tank can be included in the system to overcome this problem. However, this has not been considered in this work. In section 4 the impact of the minimal modulation rate on the results is discussed.

The coefficient of performance (COP) of the heat pump is derived from product data and depends on the condenser and evaporator temperatures and the modulation rate, as shown in Fig. 2. Note that defrosting of the evaporator may be necessary in cold and humid conditions. It is assumed that this is taken into account in the performance data of Fig. 2 .

\subsubsection{Heat emission}

The radiators are modeled using a five segment discretization. Each radiator is divided into 5 elements where the mass of each segment is lumped and assumed to have a temperature equal to the water $\left(T_{w}\right)$ at the outlet of the radiator segment. For each segment the heat emission by convection $\left(Q_{c}\right)$ and radiation $\left(Q_{r}\right)$ are calculated using the radiator equations Eq. (1) and Eq. (2):

$Q_{r}=f_{r} K_{\text {Radiator }}\left(T_{w}-T_{r, i}\right)^{n}$

Table 3

Design thermal power of the air to water heat pump for the different insulation levels and heat emission systems.

\begin{tabular}{lll}
\hline Insulation level & $Q_{\text {nom }}[\mathrm{kW}]$ radiators & $Q_{\text {nom }}[\mathrm{kW}]$ floor heating \\
\hline K20 & 9.7 & 11.5 \\
K40 & 11.0 & 13.1 \\
K60 & 12.1 & 13.3 \\
\hline
\end{tabular}

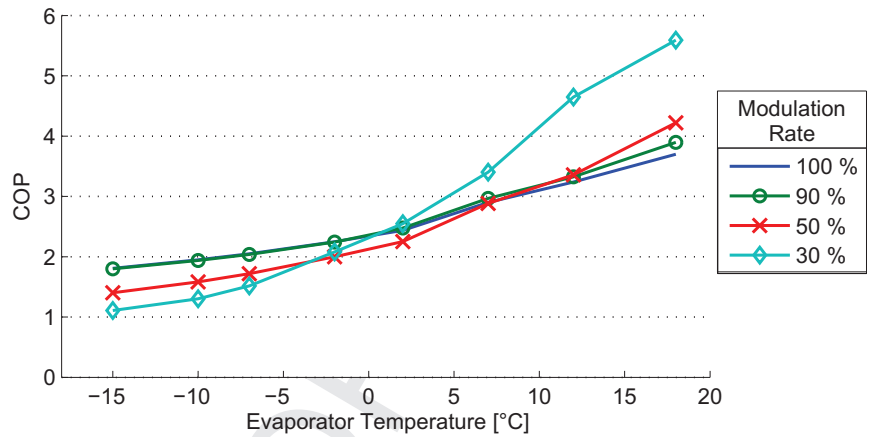

Fig. 2. COP as a function of the modulation rate and the evaporator temperature for a condenser temperature of $45^{\circ} \mathrm{C}$ based on product data.

$Q_{c}=\left(1-f_{r}\right) K_{\text {Radiator }}\left(T_{w}-T_{c, i}\right)^{n}$

where $f_{r}$ is the fraction of heat that is emitted by radiation and is assumed to be 0.3 for classic radiators, the radiator exponent $n$ is set to 1.3 according to EN442 [47] and $K_{\text {Radiator }}[\mathrm{W} / \mathrm{K}$ ] is a heat emission coefficient of the radiator. $T_{c, i}$ and $T_{r, i}$ are the air temperature and the radiant star temperature for each zone.

The dynamic heat balance equation for each element becomes:

$c_{w} \dot{m}_{w}\left(T_{w, \text { in }}-T_{w, \text { out }}\right)-Q_{r}-Q_{c}=C_{\text {Radiator }} \frac{d T_{w}}{d t}$

where $\dot{m}[\mathrm{~kg} / \mathrm{s}]$ is the mass flow rate of water running through the radiator and $c_{w}[\mathrm{~J} / \mathrm{kgK}]$ is the specific heat capacity of water. $C_{\text {Radiator }}$ $[\mathrm{J} / \mathrm{K}]$ is the heat capacity of the radiator segment. $T_{w, \text { in }}\left[{ }^{\circ} \mathrm{C}\right]$ and $T_{w, \text { out }}$ $\left[{ }^{\circ} \mathrm{C}\right]$ are the temperatures of the water flowing in and out of the segment respectively. Plug flow effects are not considered in this model. The dry mass of the radiator and the water volume are calculated from product data. The radiators are sized for a design supply temperature of $45^{\circ} \mathrm{C}$ and a return temperature of $35^{\circ} \mathrm{C}$.

The floor heating system is modeled according to EN15377 [48] and corresponding to the background of Koschenz and Lehmann [49]. The dynamic heat balance equation for the water in the floor heating system is given by Eq. (4):

$c_{w} \dot{m}_{w}\left(T_{w, \text { in }}-T_{w, \text { out }}\right)-Q_{\text {net }}=c_{w} \dot{m}_{w} \frac{d T_{w}}{d t}$

where $Q_{\text {net }}[\mathrm{W}]$ is the heat exchanged with the floor heating node inside the concrete layer.

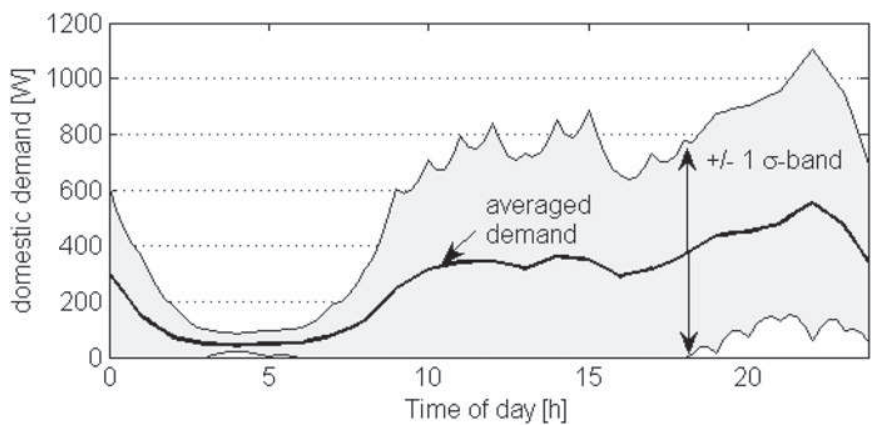

Fig. 3. Averaged daily profile of the domestic electricity demand and the confidence band for one standard deviation $(\sigma)$. 
Table 4

Estimations of available structural storage capacity.

\begin{tabular}{|c|c|c|c|c|c|c|c|c|c|c|}
\hline \multicolumn{2}{|c|}{$\begin{array}{l}\text { Construction } \\
\text { type }\end{array}$} & \multirow{2}{*}{$\begin{array}{l}\text { Living } \\
\text { room (1) } \\
42.1\end{array}$} & \multirow{2}{*}{$\begin{array}{l}\text { Kitchen (2) } \\
12.8\end{array}$} & \multirow{2}{*}{$\begin{array}{l}\begin{array}{l}\text { Office } \\
\text { room (3) }\end{array} \\
13.0\end{array}$} & \multirow{2}{*}{$\begin{array}{l}\text { Hall (5) } \\
24.9\end{array}$} & \multirow{2}{*}{$\begin{array}{l}\begin{array}{l}\text { Storage } \\
\text { room }(6)\end{array} \\
12.9\end{array}$} & \multirow{2}{*}{$\begin{array}{l}\text { Bedroom (7) } \\
22.7\end{array}$} & \multirow{2}{*}{$\begin{array}{l}\text { Bedroom (8) } \\
23.5\end{array}$} & \multirow{2}{*}{$\begin{array}{l}\text { Bedroom (9) } \\
19.4\end{array}$} & \multirow{2}{*}{$\begin{array}{l}\text { Bathroom (10) } \\
10.0\end{array}$} \\
\hline HW & $C_{\mathrm{est}, 1}[\mathrm{MJ} / \mathrm{K}]$ & & & & & & & & & \\
\hline & $C_{\mathrm{est}, 2}[\mathrm{MJ} / \mathrm{K}]$ & 5.6 & 2.1 & 1.8 & 4.6 & 1.8 & 2.8 & 3.2 & 2.5 & 1.6 \\
\hline \multirow[t]{2}{*}{ LW } & $C_{\text {est }, 1}[\mathrm{MJ} / \mathrm{K}]$ & 39.7 & 12.8 & 11.4 & 19.6 & 11.4 & 20.5 & 20.5 & 18.9 & 8.95 \\
\hline & $C_{\mathrm{est}, 2}[\mathrm{MJ} / \mathrm{K}]$ & 4.6 & 1.7 & 1.5 & 2.8 & 1.4 & 2.4 & 2.7 & 2.2 & 1.3 \\
\hline
\end{tabular}

\subsection{Control strategies}

\subsubsection{Reference control strategy}

The reference control strategy (Ref) relies on thermostatic radiator valves (TRV) to assure thermal comfort, as is current practice in Belgium [31]. Thereby the mass flow rate $\dot{m}_{w}[\mathrm{~kg} / \mathrm{h}]$ is adjusted based on the difference between the current room temperature and the temperature setpoint, according to [50]. The floor heating system is not equipped with thermostatic valves due to inaccuracies in the pipe model at very low water flow speeds. Instead, an on/off-control with a hysteresis of $0.25{ }^{\circ} \mathrm{C}$ on the operative temperature is implemented. The temperature setpoint for each room, specified in Table 2, is in line with the required comfort temperatures given in standard ISO 7730 [51].

\subsubsection{Demand-side management control}

In order to activate the structural storage capacity for DSM, dynamic control strategies are implemented. This DSM control strategy activates the heating system based on real-time data of the net domestic electric demand of the building. The net domestic demand $\left(P_{\text {dom,net }}[\mathrm{W}]\right)$ of the building is thereby defined as:

$P_{\text {dom,net }}=P_{\text {dom }}-P_{\mathrm{PV}}$

where $P_{\text {dom }}[\mathrm{W}]$ is the domestic electricity demand and $P_{\mathrm{PV}}[\mathrm{W}]$ is the electricity production from the PV system. As such, a negative value for $P_{\mathrm{dom}, \text { net }}[\mathrm{W}]$ corresponds to a period where the PV production exceeds the domestic demand. The threshold values for the net electricity demand at which the DSM-control will be activated, i.e. $P_{\min }$ and $P_{\max }$, are set to $0 \mathrm{~W}$ and $500 \mathrm{~W}$, meaning that on the one hand the HP will be activated to preheat the building whenever the PV production is higher than the domestic load. On the other hand the temperature setpoint will be reduced to $T_{\min }$ when the domestic load exceeds the PV production by $500 \mathrm{~W}$. A temperature bandwidth of $2{ }^{\circ} \mathrm{C}$ is allowed on the comfort temperatures, specified in Table 2, to allow for the sensible heat storage. This bandwidth corresponds to the temperature deviations that are allowed by comfort class A in ISO 7730 [29]. As such a conservative approach is used for the evaluation of the DSM potential.

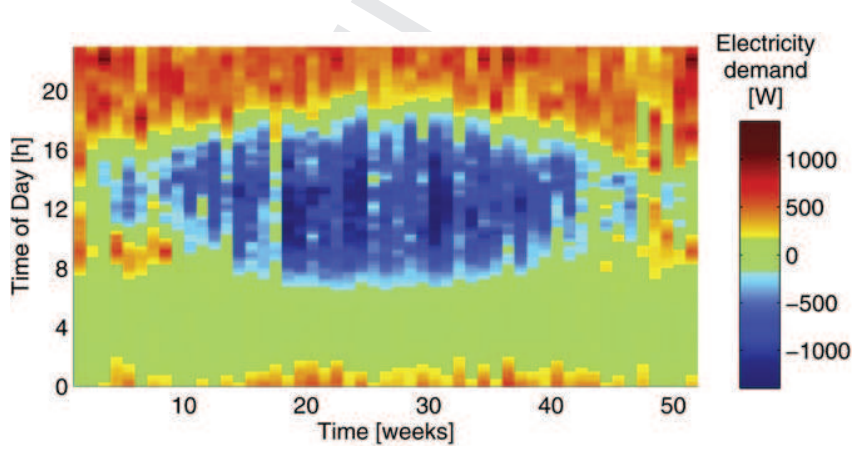

Fig. 4. Net electricity demand $\left(P_{\text {dom,net }}\right)$ with PV system sized to cover domestic load.
As preheating the building during peak supply periods results in an elevated energy use for heating, the efficiency of the control strategy is expected to depend upon the efficiency to which the increased HP use during peak supply periods can be compensated by electricity demand reductions for heating and efficiency gains during peak demand periods. Therefore control strategies that take into account the predicted heat demand to avoid overcharging are expected to be more efficient.

The influence of the DSM control strategy is evaluated by analyzing two DSM strategies. A first approach, referred to as nonpredictive control, uses the entire comfort band by increasing the set temperature to $T_{\max }$ whenever excess PV electricity is available. In the second approach, the elevated temperature setpoint is calculated by means of model-based control, to reduce elevated heat losses by avoiding overcharging of the thermal mass. Based on Fourier's law an expression linking the preheat set temperature $\left(T_{\text {set }}\right)$, the available thermal mass of the building $\left(C_{\mathrm{eff}}\right)$ and the predicted heat loss $\left(Q_{\text {pred }}\right)$ can be established:

$T_{\text {set }}=T_{\text {min }}+\frac{\int_{0}^{t_{\text {off }}} Q_{\text {pred }} d t}{C_{\text {eff }}}$

where $T_{\min }\left[{ }^{\circ} \mathrm{C}\right]$ is the minimal comfort temperature during the occupied period. The integration period $\left(t_{\text {off }}\right)$ is set to $5 \mathrm{~h}$. This period would allow to overcome the high domestic demand between 17:00 and 22:00 shown in Fig. 3, without the room temperature falling below the minimal comfort temperature.

Two different estimations of the thermal storage capacity of the building $\left(C_{\text {eff }}[\mathrm{MJ} / \mathrm{K}]\right)$ have been made. The first method $\left(\operatorname{Qpred}_{A}\right)$ assumes that the complete structure contributes to the active storage capacity. In that case, the estimation for $C_{\text {eff }}$ is based on the design values of the building's structure, as given by Eq. (7):

$C_{\mathrm{eff}, A}=\sum_{i=\text { elements }} \rho_{i} c_{i} V_{i}$

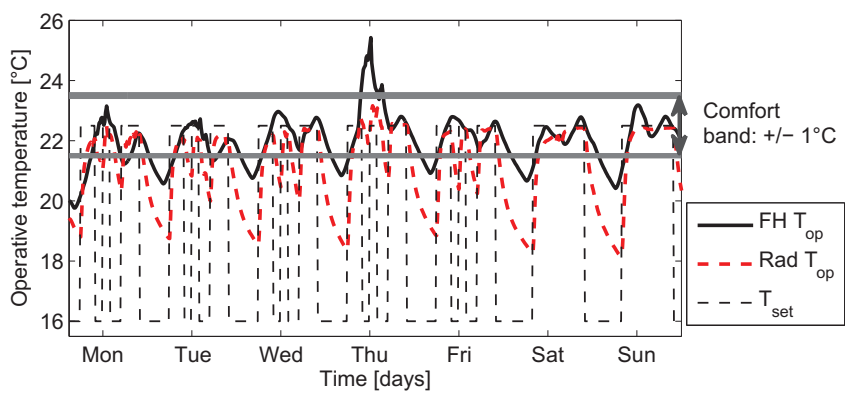

Fig. 5. Comparison between the temperature profile obtained with the floor heating system (FH) and the radiator system (Rad) for typical winter week. The $\pm 1{ }^{\circ} \mathrm{C}$ comfort band for the occupied periods is shown. 
where for each construction element $i, \rho_{i}$ is the density, $c_{i}$ is the specific heat capacity and $V_{i}$ is the volume. As such this estimation consists of rules of thumb and design values and can merely be a rough approximation of the dynamic behavior, typically overestimating the available thermal storage capacity. In contrast, the second method $\left(\operatorname{Qpred}_{B}\right)$ estimates the effective capacity from detailed simulations of a step-up heating experiment, using an ideal convective heating system. For each wall the energy stored within the structure is calculated as the difference between the heat flux at the interior $\left(Q_{s, i, i n t}\right)$ and the heat flux at the exterior surface $\left(Q_{s, i, \text { ext }}\right)$ of wall $i$. The effective capacity $C_{\text {eff }}$ is then given by Eq. (8). Table 4 summarizes the estimated capacity for each method.

$C_{\mathrm{eff}, B} \frac{d T_{\mathrm{op}}}{d t}=\sum_{i=\text { elements }}\left(Q_{s, i, \text { int }}-Q_{s, i, \mathrm{ext}}\right)+C_{\mathrm{air}} \frac{d T_{\mathrm{op}}}{d t}$

The predicted heating demand $\left(Q_{\text {pred }}\right)$ is estimated using the detailed building model. This estimation assumes that future weather data as well as future internal gains are perfectly known at the current time step. The heat demand is then predicted by the energy demand of an ideal heating system that maintains a constant temperature equal to the zonal set temperatures specified in Table 2.

\subsection{Evaluation criteria}

The potential for DSM using structural storage is quantified by the ability to improve the cover factor of the PV system and to shift the peak electricity demand of the HP by using structural thermal storage.

Thereby the demand cover factors $\gamma_{d}$ is defined as "the ratio to which the electricity demand is covered by the PV supply", whereas the supply cover factor $\gamma_{s}$ is defined "the ratio to which the PV supply is covered by the electricity demand", expressing the grid dependency of a nZEB [52]:
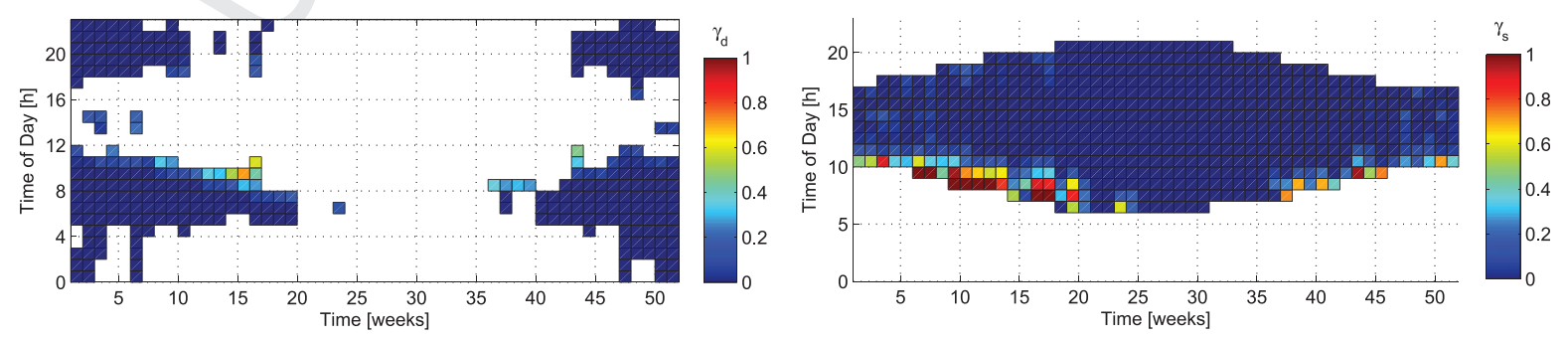

Fig. 7. Demand cover factor $\left(\gamma_{d}\right)$ (left) and supply cover factor $\left(\gamma_{s}\right)$ (right) of the heat pump system with the reference control for floor heating for the K40-building.

$$
\gamma_{d}=\frac{\int_{t_{1}}^{t_{2}} \min \left(P_{\mathrm{PV}}, P_{d}\right) d t}{\int_{t_{1}}^{t_{2}} P_{d} d t} \text { and } \gamma_{s}=\frac{\int_{t_{1}}^{t_{2}} \min \left(P_{\mathrm{PV}}, P_{d}\right) d t}{\int_{t_{1}}^{t_{2}} P_{\mathrm{PV}} d t}
$$

Here, $P_{\mathrm{PV}}[\mathrm{W}]$ denotes the supply power from the PV system and $P_{d}[\mathrm{~W}]$ the electricity demand for space heating and domestic use.

In addition to the cover factors, it is important to analyze peaks in the electricity demand from and the supply towards the electricity grid. Peak demand and supply will have an important impact on the stability of the electricity network [9]. In this paper the influence of DSM on the annual energy use of the HP during peak supply and peak demand periods is quantified. Load duration curves for the HP systems are calculated to investigate the influence of DSM on the power spectrum of the HP demand.

Since the activation of the structural storage capacity might result in increased thermal losses, the change in the total annual electricity use of the dwelling is calculated and compared for all scenarios. In this way the potential costs or gains resulting from DSM using the structural thermal storage can be quantified.

In order to evaluate the impact of the control strategies on thermal comfort a 'weighted temperature deviation (WTD)' [Kh] is calculated. A distinction has been made between periods with temperatures exceeding the comfort temperature and periods with temperatures below the comfort temperature, denoted as $W T D_{H}$ and $W T D_{L}$, respectively.

$$
\begin{aligned}
& W T D_{L}=\int_{T_{\mathrm{op}}<T_{\min }}\left|T_{\mathrm{op}}-T_{\min }\right| d t \\
& W T D_{H}=\int_{T_{\mathrm{op}}>T_{\max }}\left|T_{\mathrm{op}}-T_{\max }\right| d t
\end{aligned}
$$



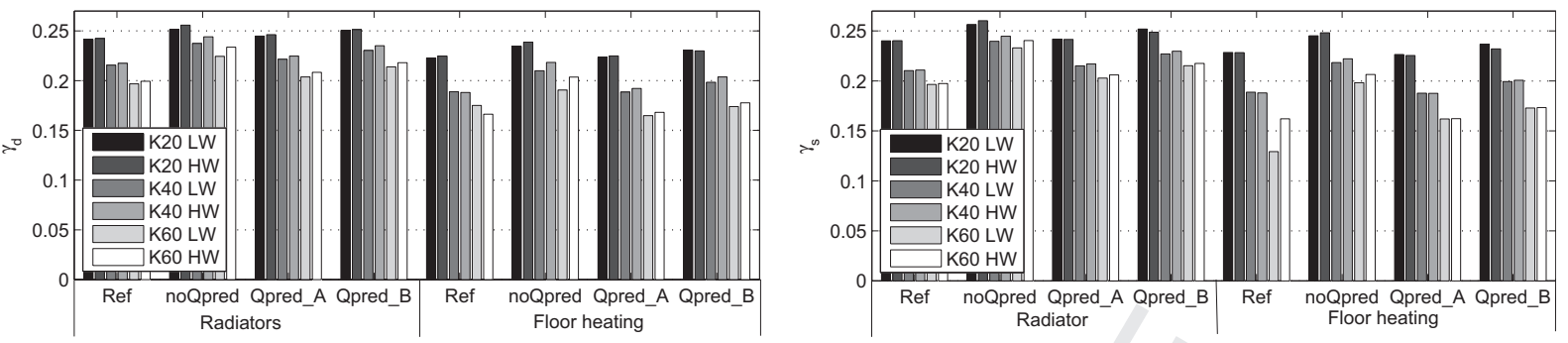

Fig. 8. Demand cover factor $\left(\gamma_{d}\right)$ (left) and supply cover factor $\left(\gamma_{s}\right)$ (right) for total electricity use.

Thereby, $T_{\mathrm{op}}$ denotes the room temperature and $T_{\min }$ and $T_{\max }$ represent the comfort boundaries. The comfort temperature for each zone is specified in Table 2. Note that a distinction is made between bathrooms, bedroom and other rooms as suggested by Peeters et al. [31]. However as it could be argued that DSM might limit the possibilities of the user to adapt to the thermal environment (eg. by opening windows), adaptive comfort criteria are not taken into account. The allowed temperature deviations, needed to activate the thermal storage capacity, are limited to a bandwidth of $2{ }^{\circ} \mathrm{C}$ around the comfort temperature in accordance with comfort class A in ISO 7730 [29]. As shown in Fig. 5, small differences between the indoor temperature profiles for the different control strategies and heating systems can exist. These deviations will not be evaluated as uncomfortable when the deviations during the occupied period stay within the $2{ }^{\circ} \mathrm{C}$ comfort band.

\section{Results}

The most important results are summarized in this section. The mismatch between the domestic electricity demand and the PV production is shown in section 3.1. Section 3.2 shows how this mismatch increases when the electricity use for heating is included and the PV system is sized to cover both the annual domestic use and the annual electricity use for heating. The potential for DSM using structural storage is quantified in section 3.3. The influence of the control strategies and the thermal properties of the building on the DSM potential are shown in section 3.3.1 and 3.3.2.

\subsection{Domestic electricity use and local PV production}

Domestic electricity use is calculated from stochastic user data as described in [3]. The data include the stochastic load from appliances and lighting and result in an annual use of $2400 \mathrm{kWh}$, in line with Belgian statistics.

A PV system of $2.76 \mathrm{kWp}$ is able to achieve the net zero energy level. However, a mismatch between supply and demand is shown throughout the year (Fig. 4). This figure shows the variation of the averaged daily demand profile throughout the year. The profile has been averaged over each week. High negative values are shown in summer, between 10:00 and 17:00, when the PV output is high. In contrast, domestic demand peaks are concentrated in the evening, illustrating the mismatch.

On an annual basis a cover factor of 0.31 is obtained when the PV system is sized to cover the annual domestic electricity use without DSM measures. This result is in line with [3] and demonstrates the strong grid dependency of a nZEB, since $69 \%$ of the PV production needs to be injected in the electricity network, using the grid as virtual storage.

\subsection{Local PV production and heating demand with reference control}

The annual electricity use for heating is found to be respectively $1265 \mathrm{kWh}\left(6.32 \mathrm{kWh} / \mathrm{m}^{2}\right), 2183 \mathrm{kWh}\left(10.92 \mathrm{kWh} / \mathrm{m}^{2}\right)$ and $3094 \mathrm{kWh}\left(15.47 \mathrm{kWh} / \mathrm{m}^{2}\right)$ for the massive K20-, K40- and $\mathrm{K} 60$ building with radiators, using the reference control without DSM. The sizes of the corresponding PV systems designed to cover the annual domestic use and the HP electricity use, are $4.14 \mathrm{kWp}$, $5.29 \mathrm{kWp}$ and $6.44 \mathrm{kWp}$ or 18,23 and 28 panels, respectively. For the floor heating system, the electricity use is higher caused by the higher overall temperature as shown in Fig. 5. This higher overall temperature is on the one hand caused by a longer preheat period that is implemented to recover from night-setback. On the other hand the large time constant of the system results in inefficient behavior of the thermostatic control. As a result, the annual electricity use for heating has increased by $23 \%$ and is found to be $1565 \mathrm{kWh}\left(8.80 \mathrm{kWh} / \mathrm{m}^{2}\right), 2666 \mathrm{kWh}\left(14.99 \mathrm{kWh} / \mathrm{m}^{2}\right)$ and $3808 \mathrm{kWh}\left(21.42 \mathrm{kWh} / \mathrm{m}^{2}\right)$ for the massive K20-, K40- and $\mathrm{K} 60$ dwelling, respectively. The corresponding PV systems consist of 19, 27 and 31 panels or $4.37 \mathrm{kWp}, 6.21 \mathrm{kWp}$ and $7.13 \mathrm{kWp}$, respectively.

Figs. 6 and 7 show the demand cover factor and supply cover factor throughout the year for the massive K40-building for the radiator and the floor heating case respectively. Taking into account that $\gamma_{d}$ and $\gamma_{s}$ can only be calculated during periods when respectively the electricity load for heating and the PV production

Table 5

Heat pump electricity use [kWh] during peak demand periods for the 3 insulation levels (K20-K60) and the light-weight (LW) and heavy-weight (HW) building as function of the control strategy and the heat emission system.

\begin{tabular}{|c|c|c|c|c|c|c|c|}
\hline \multirow[t]{2}{*}{ Building type } & & \multicolumn{2}{|l|}{ K20 } & \multicolumn{2}{|l|}{ K40 } & \multicolumn{2}{|l|}{ K60 } \\
\hline & & LW & HW & LW & HW & LW & HW \\
\hline \multirow[t]{4}{*}{ Radiators } & Ref & 196 & 201 & 352 & 364 & 487 & 510 \\
\hline & noQpred & $59(-70 \%)$ & $49.8(-75 \%)$ & $129(-63 \%)$ & $119(-67 \%)$ & $215(-56 \%)$ & $197(-61 \%)$ \\
\hline & Qpred $_{A}$ & $84.8(-57 \%)$ & $79.7(-60 \%)$ & $186(-47 \%)$ & $181(-50 \%)$ & $294(-40 \%)$ & $291(-43 \%)$ \\
\hline & Qpred $_{B}$ & $63.4(-68 \%)$ & $63.4(-68 \%)$ & $156(-56 \%)$ & $146(-60 \%)$ & $264(-46 \%)$ & $263(-48 \%)$ \\
\hline \multirow[t]{4}{*}{ Floor Heating } & Ref & 155 & 150 & 294 & 285 & 426 & 434 \\
\hline & noQpred & $14.7(-91 \%)$ & $9.62(-94 \%)$ & $32.2(-89 \%)$ & $28.4(-90 \%)$ & $31.3(-93 \%)$ & $30.7(-93 \%)$ \\
\hline & Opred $_{A}$ & $37.1(-76 \%)$ & $31.2(-79 \%)$ & $94(-68 \%)$ & $83.2(-71 \%)$ & $163(-62 \%)$ & $122(-72 \%)$ \\
\hline & Qpred $_{B}$ & $22(-86 \%)$ & $18.2(-88 \%)$ & $49.5(-83 \%)$ & $46.8(-84 \%)$ & $96(-77 \%)$ & $82.4(-81 \%)$ \\
\hline
\end{tabular}


Table 6

Heat pump electricity use [kWh] during peak supply periods for the 3 insulation levels (K20-K60) and the light-weight (LW) and heavy-weight (HW) building as function of the control strategy and the heat emission system.

\begin{tabular}{|c|c|c|c|c|c|c|c|}
\hline \multirow[t]{2}{*}{ Building type } & & \multicolumn{2}{|l|}{ K20 } & \multicolumn{2}{|l|}{ K40 } & \multicolumn{2}{|l|}{ K60 } \\
\hline & & LW & HW & LW & HW & LW & HW \\
\hline \multirow[t]{4}{*}{ Radiators } & Ref & 188 & 205 & 382 & 376 & 589 & 547 \\
\hline & noQpred & $542(+188 \%)$ & $585(+185 \%)$ & $999(+162 \%)$ & $1040(+177 \%)$ & $1400(+138 \%)$ & $1380(+152 \%)$ \\
\hline & Qpred $_{A}$ & $244(+30 \%)$ & $254(+24 \%)$ & $524(+37 \%)$ & $531(+41 \%)$ & $784(+33 \%)$ & $762(+39 \%)$ \\
\hline & $\operatorname{Qpred}_{B}$ & $431(+129 \%)$ & 369 (+80\%) & $727(+90 \%)$ & $732(+95 \%)$ & $979(+66 \%)$ & $928(+70 \%)$ \\
\hline \multirow[t]{4}{*}{ Floor Heating } & Ref & 132 & 141 & 243 & 231 & 340 & 301 \\
\hline & noQpred & $550(+317 \%)$ & $599(+325 \%)$ & $1200(+394 \%)$ & $1209(+423 \%)$ & $1670(+391 \%)$ & $1670(+455 \%)$ \\
\hline & Qpred $_{A}$ & $120(-9 \%)$ & $110(-22 \%)$ & $260(7 \%)$ & $235(2 \%)$ & $362(6 \%)$ & $356(18 \%)$ \\
\hline & $\operatorname{Qpred}_{B}$ & $350(+165 \%)$ & $259(+84 \%)$ & $555(+128 \%)$ & $549(+138 \%)$ & $712(+109 \%)$ & $665(+121 \%)$ \\
\hline
\end{tabular}

exist, $\gamma_{d}$ for the floor heating system (Fig. 7) shows how the HP electricity demand is concentrated in the morning and evening. During these periods the PV production is small or even zero, as shown by the supply cover factor $\left(\gamma_{s}\right)$, demonstrating the mismatch between the electricity demand for heating and the local PV production. The radiator system (Fig. 6) shows a wider spread of the heat demand, increasing $\gamma_{d}$. This effect can be explained by the more rapid temperature fluctuations for the radiator system (Fig. 5), indicating that the radiators are not effectively activating the thermal mass embedded in the structure, as they primarily heat up the indoor air.

Annual cover factors of the HP electricity use for the K20, K40 and $\mathrm{K} 60$-building are $2.0 \%, 2.7 \%$ and $3.0 \%$ for the floor heating system and $4.6 \%, 6.4 \%$ and $7.3 \%$ for the radiator system respectively, indicating that up to $98 \%$ of the electricity used for space heating is delivered by the electricity network rather than the local PV production. Note that the annual cover factor for the K20-building is lower than for the K60-building. This can be explained by pointing out that for the K60-building a heat demand is still showing during the mid-season, whereas the heat demand of the K20-building is concentrated on cold winter days. For the well insulated K20dwelling passive solar gains will be able to heat the buildings more easily, reducing the electricity demand for heating when PV electricity is available and thus increasing the mismatch.

In contrast, the cover factors for the total electricity use (Fig. 8) are smallest for the less insulated K60-building, since the contribution of electricity use for heating, characterized by very low cover factors, is higher for the less insulated buildings. Moreover, the K60-building shows higher peaks in the electricity demand and supply, due to the higher nominal power of the HP and the higher number of PV panels. The total electricity use of the HP during peak demand periods $\left(P_{\text {dom,net }}>500 \mathrm{~W}\right)$ is shown in Table 5 . Again the highest HP electricity use during domestic peak demand periods is found for the K60-building. Therefore the conversion of less insulated buildings to nZEBs by installing additional PV panels, is expected to have a high impact on the grid stability, since high peaks in the demand and supply induce fluctuations of the frequency and voltage levels in the electricity network.

\subsection{Evaluation of DSM potential of structural storage}

To evaluate the DSM potential of structural storage, DSM-control strategies, described in section 2.4 , are evaluated for their ability to reduce the strong grid dependence of a nZEB shown in the previous section.

The first control strategy suggested in section 2.4 is the nonpredictive control strategy (noQpred). Table 5 shows that the DSM-control is able to reduce the heat pump activity during peak demand periods significantly. For the radiator heating system, the HP electricity use during demand peak periods is reduced by $56-$ $75 \%$. For the floor heating scenarios reductions between $89 \%$ and $94 \%$ are obtained.

Alternatively, the DSM-control increases the HP activity when the PV output grows the domestic demand in order to activate the thermal mass (Table 6.

Again the floor heating system is found beneficial for the peak shifting potential, since it allows the heat pump to remain active for a longer period before the elevated room temperature setpoint is reached. As a result more energy is stored inside the thermal mass within the same indoor temperature interval compared to the heating system with radiators.

Since the non-predictive control strategy does not take into account the predicted heat demand, more energy will be stored into the thermal mass than is necessary to guarantee thermal comfort. Consequently, the non-predictive control strategy shows the highest influence on the cover factors and the electricity use of the HP during peak periods (Fig. 8 and Table 5). As a major drawback, this approach also gives rise to the highest total energy use, as shown in Fig. 9. For the radiator system an increase in the annual electricity use for heating between $6.7 \%$ and $7.9 \%$ is found for the different building cases. For the floor heating system, DSM results in an increase of $5.0 \%-7.3 \%$ for the K20- to K60-dwelling. Therefore, it is evident that DSM using the structural storage comes at a high cost, especially for the less insulated buildings.

Fig. 10 shows how overcharging induces higher indoor temperature as the noQpred-control increases the $W T D_{H}$ and decreases $W T D_{L}$ for the bandwidth of $2{ }^{\circ} \mathrm{C}$. For the radiator heating $W T D_{H}$ 
increases with $4.6 \%-9.9 \%$ for the K20- and K60-building respectively. For the floor heating system the increase in the temperature is stronger, with an increase of $W T D_{H}$ between $9.5 \%$ and $23 \%$, illustrating that thermal comfort decreases with lower insulation levels and slow reacting heating systems. The highest increase is found for the K60-building. In this case the non-predictive control activates the HP also during the mornings in mid-season, charging the thermal mass. Consequently, overheating occurs when solar gains enter the rooms during the day.

The influence of the shift in HP use on the hourly demand cover factors for the massive K40-building is shown in Fig. 11. A comparison of Fig. 11 with the results from the reference control (left panels of Figs. 6 and 7) shows that the DSM-control is able to shift part of the HP electricity use during periods with high domestic demand to periods where PV electricity is available, resulting in an increase of $\gamma_{d}$. The increase in $\gamma_{d}$ is most clear for the radiator system and can again be attributed to the more rapid temperature fluctuations. For the floor heating system the HP electricity use remains concentrated in the morning and evening. As a result the fraction of the electricity use that is covered by PV electricity $\left(\gamma_{d}\right)$ is smaller than for the radiator heating system, as observed in Fig. 11. During the cold winter weeks, the DSM-control even results in a reduction of the hourly $\gamma_{d}$ for the K40-building with floor heating, due to the fact that HP is activated at high electricity loads, as shown in Fig. 13. Consequently, the electricity demand of the HP exceeds the PV production, reducing $\gamma_{d}$.

Fig. 8 shows the resulting annual averaged cover factors for the $\mathrm{HP}$ electricity use. Compared to the reference control, implementing a non-predictive DSM control employing the structural storage capacity of buildings, improves the cover factor of the K20-, K40and $\mathrm{K} 60$-building by $1.7 \%, 3.4 \%$ and $4.3 \%$ for the radiator case and $2.0 \%, 3.4 \%$ and $4.4 \%$ for the floor heating case. The increase is higher for less insulated, heavy-weight buildings with slow reacting heating systems, since for these cases the heating can be activated for longer periods, even during mid-season. Nevertheless, in absolute value the cover factors decrease for decreasing insulation qualities, since for less insulated cases the contribution of the HP and the floor heating system (right).

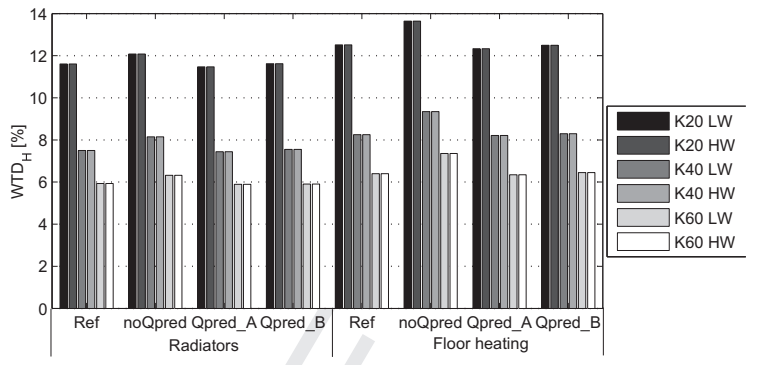

electricity use in the total electricity use is higher. Although DSM using the structural storage increases the cover factors and reduces the differences between the different insulation levels, the mismatch between the total demand and the PV production is still highest for less insulated buildings.

\subsubsection{Influence of model based control strategies}

Figs. 12 and 13 illustrate the influence of model based control strategies on the demand shifting potential for the radiator system and the floor heating system. Two important effects are shown. Firstly, during peak supply periods $\left(P_{\text {dom,net }}<P_{\min }\right)$ a reduction of the activation of the HP at high operating power is shown, which was obtained for the non-predictive controller, indicating that the model based control reduces preheating during the morning, by taking into account the future heat demand of the building. As such the model based control postpones the charging of the structural storage to the afternoon, reducing HP use at high operating power.

Secondly, Figs. 12 and 13 show that the increase in the HP operation during peak supply periods and the decrease of the HP operation during peak demand periods is smallest for the $\operatorname{Qpred}_{A^{-}}$ control which assumes that the entire thermal mass is activated. This effect demonstrates how this assumption overestimates the structural storage capacity and results in insufficient preheating. Consequently, the domestic peak periods can not be bridged, illustrated by smaller reductions of the HP operation during the peak demand periods (Table 5). For the cases with radiator heating reductions in the peak HP use between $39.6 \%$ and $60.35 \%$ are found for the Qpred $_{A}$-control and $45.7 \%$ and 68.7\% for the Qpred $_{B}$-control. Using the floor heating system the $\operatorname{Qpred}_{A}$-control results in reductions of $61.7 \%$ and $79.2 \%$, whereas the Qpred $_{B}$-control reduces the peak HP use by $77.5 \%-87.9 \%$. Improving the prediction in the model based control thus increases the DSM potential. However, the load-duration curve is still above the curve obtained for the non-predictive control strategy, indicating that the predicted heat demand is still underestimated and further improvements to the calculation of the setpoint temperature should be considered.

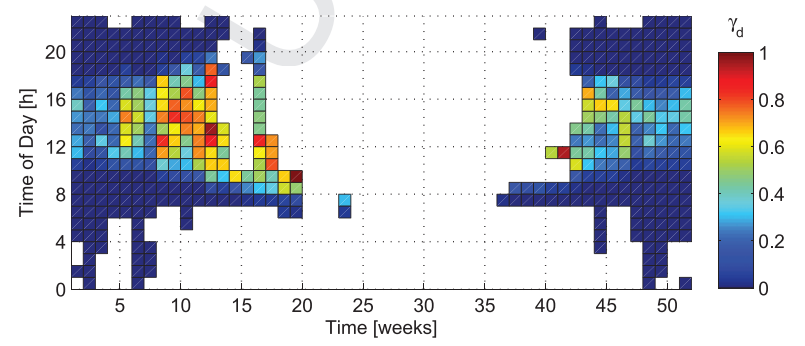

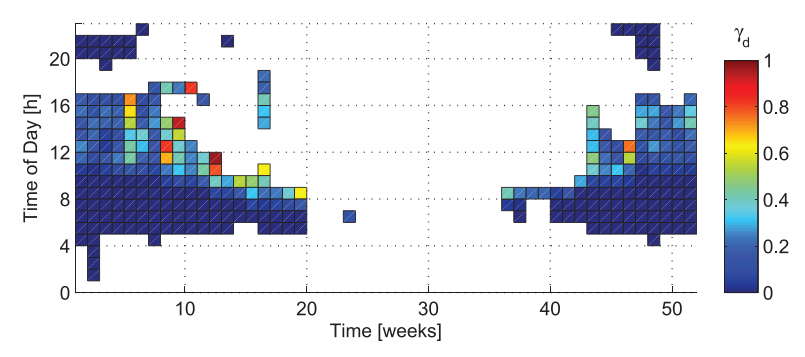

Fig. 11. Demand cover factor $\left(\gamma_{d}\right)$ of the heat pump system with the non-predictive control strategy for the massive K40-building equipped with the radiator heating systems (left) 
The reduced HP operation during peak supply periods also influences the cover factors. Fig. 8 shows how the increase in $\gamma_{d}$ and $\gamma_{s}$ is smaller for the predictive control strategies compared to the non-predictive control.

The influence of the control strategy on the total energy use for heating is shown in Fig. 9. The influence of DSM on the total energy use of the building is less pronounced for the predictive control strategies than for the non-predictive control. For the $\operatorname{Qpred}_{A^{-}}$ control even a minor decrease of the electricity use is found, indicating the reduction of electricity use due to the reduction of the set temperature during peak demand periods is more important than the increased electricity use during peak supply periods. Fig. 10 shows how this effect can be explained by the change in the indoor temperature. While the non-predictive control strategy resulted in higher indoor temperatures, the use of model based control pushes the indoor temperature towards the minimal comfort boundary. Nonetheless, the increase of $\mathrm{WTD}_{L}$ compared to the reference control is less then $1 \%$ for the massive building, showing that DSM does not jeopardize thermal comfort.

\subsubsection{Influence of thermal properties of the building}

To estimate the influence of the thermal properties of the building, 3 different insulation levels have been considered for both a heavy-weight and a light-weight construction. The results discussed above show how the heavy-weight building shows higher potential for DSM compared to the light-weight cases. For all DSMcontrol strategies and all insulation qualities, the increase in $\gamma_{d}$ and $\gamma_{s}$ is more pronounced for the massive building cases (Fig. 8). Although the difference are small, Table 5 shows how the HP electricity use is reduced further for the heavy-weight building during peak demand periods, illustrating that availability of additional thermal mass allows the HP to remain off for longer periods.

Considering the insulation level of the building, the effects in the results are less obvious. The influence of the insulation quality in the cover factors is shown in Fig. 8. Note that the increase of the annual cover factor for the K20-building is lower than for the K60building. This can be explained by the fact that for the K60-building heating is still required during mid-season, whereas the heat demand of the K20-building is concentrated during the cold winter days. Nevertheless, the peak load of the K60-building is higher compared to the better insulated buildings. The load-duration curves (Figs. 12 and 13) show how improving the insulation level reduces the peaks in the electricity load of the heat pump. For the K60-building peak loads of $4100 \mathrm{~W}$ and $4700 \mathrm{~W}$ are shown for the radiator system and the floor heating system respectively. For the K20-building the peak load reduces to $3000 \mathrm{~W}$ and $2500 \mathrm{~W}$ respectively. Fig. 13 also shows that the non-predictive control strategy is able to increase the load duration at high power demands for longer period when the insulation level is low. As such, a less insulated building results in a higher annual electricity use during moments when excess PV is available (Table 5), indicating more energy is shifted values from periods with high domestic demand to periods with excess PV production. Consequently, the self consumed PV production is highest for the massive K60building (Fig. 9). As a major drawback, DSM for the less insulated buildings equipped with floor heating also results in the highest increase of the annual electricity use, as shown in Fig. 3, indicating that a larger fraction of the stored heat is lost for less insulated buildings. This figure also shows a decreasing electricity use as the available thermal mass increases.

The minimum electricity use of the HP during peak demand periods is found for the K20-building, due to the smaller heat demand of the building. For the $\operatorname{Qpred}_{B}$-control (Table 5), reductions in the electricity use of the HP during demand peak periods of $67.5 \%, 59.9 \%$ and $48.4 \%$ are obtained for the massive $\mathrm{K} 20-$-, K40- and K60-building with radiator heating, respectively. As such it can be concluded that where in absolute values less insulation results in a higher shift in the electricity use, the relative reduction is more
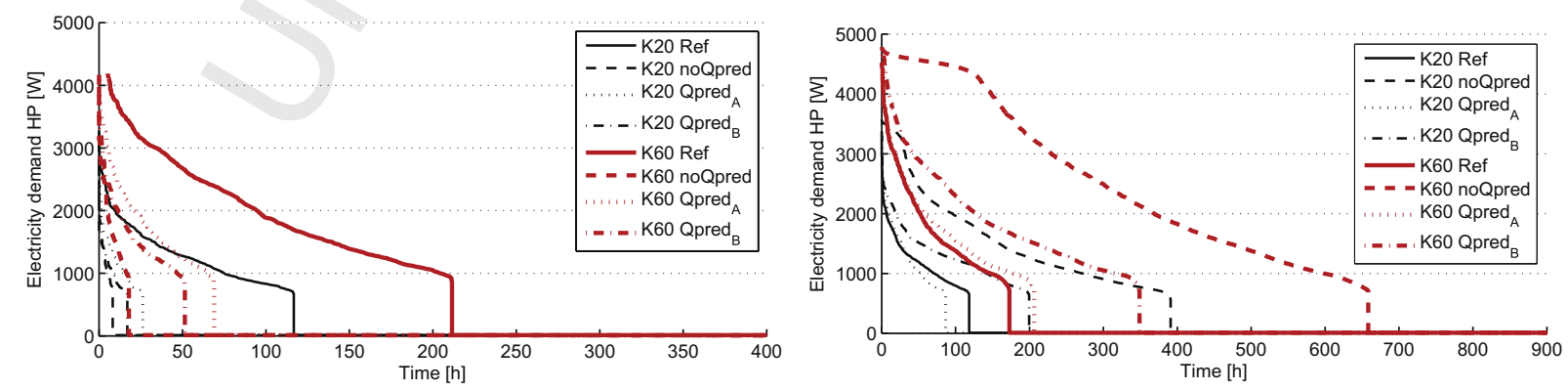

Fig. 13. Load duration curves for the different insulation qualities (K20-K60) and control strategies during peak demand periods $\left(P_{\text {dom,net }}>P_{\text {max }}\right)($ left) and peak supply periods $\left(P_{\text {dom,net }}<P_{\min }\right)$ (right) for the floor heating system use. 
pronounced for the well insulated K20-building, resulting in the lowest peak demand.

\section{Discussion}

The results show that DSM using the structural thermal storage capacity is able to shift the HP operation from peak demand periods to peak supply periods, resulting in a significant reduction of the HP electricity use during domestic peak periods. However, it is evident that the use of the thermal mass of a dwelling only enables shortterm storage and can not reduce the seasonal mismatch that is found between the heat demand of the dwelling and the PV production. To counter this seasonal mismatch long term storage would be required. Nevertheless, a strong short-term flexibility is shown to shift the electricity use for heating without jeopardizing thermal comfort.

In the introduction it has been argued that thermal comfort criteria can impose an important limitation to the DSM potential. Simulations have been carried out to evaluate the change in the reductions of the electricity use during peak demand periods for the K40-building equipped with the radiator system, when the comfort band is changed from comfort class A to class B (ISO 7730), ie. from $2{ }^{\circ} \mathrm{C}$ to $4{ }^{\circ} \mathrm{C}$. For the non-predictive control the peak use is reduced by $89.2 \%$ for the $4{ }^{\circ} \mathrm{C}$ comfort band, compared to $67.3 \%$ for the $2{ }^{\circ} \mathrm{C}$ comfort band. For the predictive control strategy the reduction is less pronounced. For the $4{ }^{\circ} \mathrm{C}$ comfort band the peak use is reduced by $79.1 \%$ compared to $59.9 \%$ for the $2{ }^{\circ} \mathrm{C}$ comfort band. In the mid-season, due to the minimal modulation rate of $30 \%$, the HP was often not activated to preheat the storage capacity. Fig. 14 shows how reducing the minimal modulation rate to $5 \%$ increases the covered PV production. This effect can be explained by the activation of the HP in mid-season when the heat demand of the building is small. Fig. 15 shows the peak demand is reduced significantly. For the reference control, this effect shows that the higher flexibility of the HP results in a wider spread of the electricity demand over the day, indicating that the DSM potential can be improved by using more flexible heat pumps.

In a Smart Grid context this flexibility could reduce the simultaneity between the electricity demand for heating and the domestic demand as well as the simultaneity between the electricity demand for heating in different buildings. Thereby reducing peaks in the electricity demand and shifting the demand towards periods where the primary efficiency of the electricity production is higher, increasing the overall efficiency at network level. Note that this increase in overall efficiency is a fundamental requirement to enable DSM using structural storage in a sustainable way, since the results show that DSM comes at a high cost since, depending on the control strategy and the thermal characteristics of the building, up to $40 \%$ of the stored energy is lost. These additional losses need to be compensated by for example a more efficient use of renewable

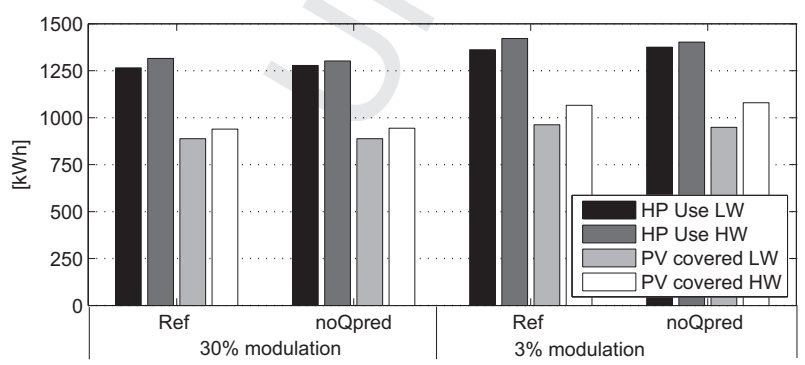

Fig. 14. Influence of the modulation rate of the HP on the annual heat pump electricity use and self-consumed PV production for the heavy-weight K20-building equipped with radiator heating.

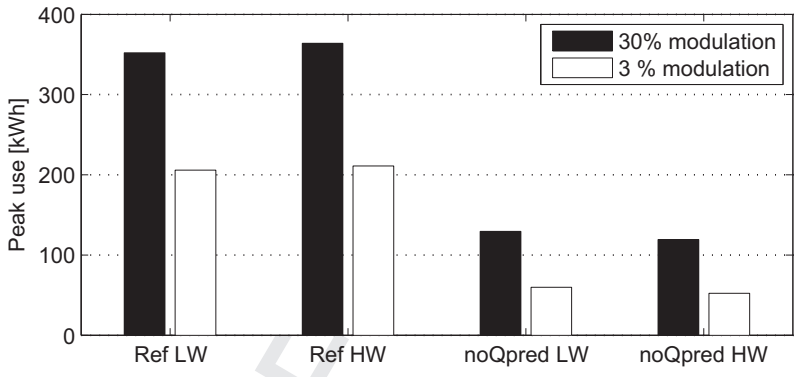

Fig. 15. Influence of the modulation rate of the HP on the electricity use during peak demand periods for the heavy-weight K20-building equipped with radiator heating.

energy sources in the Smart Grid environment. For example DSM can be used to increase the self)consumption of the PV production avoiding that PV units have to be cut off from the electricity network to prevent network instability when the renewable production is high. Fig. 16 shows the loss of PV production due to this cut off as function of the maximum supply power or cut off power that is allowed to guarantee network stability. The results demonstrate that for weak feeders (cut off power below $2000 \mathrm{~W}$ [3]) significant PV production is lost due to network limitations. DSM using the structural storage is able to reduce these losses. However, the influence is limited since most of the production is lost in summer when no heating is required.

The results also point out that transforming existing buildings into nZEB's by adding a high amount of PV panels, imposes an important impact on the electricity network. It was found that the less insulated K60-building gives rise to the highest peaks in both electricity demand as the electricity flow towards the grid. Although the application of DSM for the K60-building results in the highest shift in electricity use from periods with high domestic demand to periods with high PV output, the relative reduction in the peak use is more pronounced for the K20-building. As such it can be argued that a first step in creating a nZEB should always try to reduce the demand.

Finally, it can be argued that the optimization of the design of a nZEB on building level and on network level might result in different solutions. Whereas from a building perspective the annual balance between demand and supply is the main design and optimization criteria, the instantaneous balance becomes more important when including the limitations of the electricity network. In the case study presented in this paper, where the nZEB is created by coupling a heating system with a link to the electricity grid (i.e. an air-to-water heat pump) to a PV system, the instantaneous balance is violated due to an important seasonal mismatch. This mismatch could be tackled by for example taking active

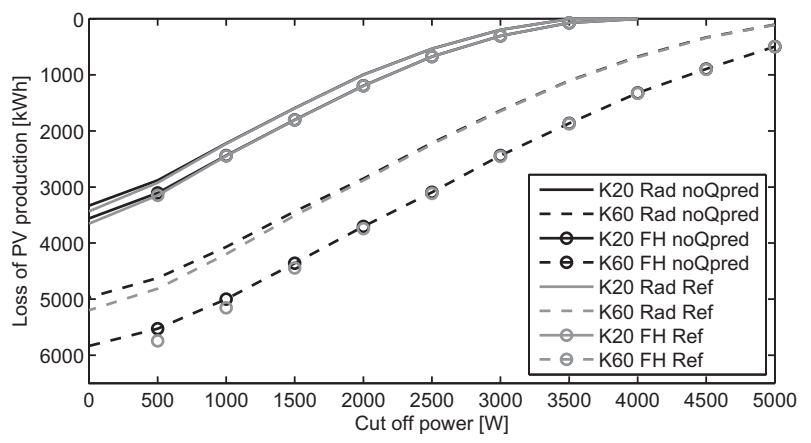

Fig. 16. Influence of DSM on the loss of PV production due to limitations on the supply power at electricity network level. 
cooling into account. As such the optimal building design might result in higher insulation levels that further reduce the heat demand of the dwelling and stimulate the use of active cooling when the PV output is high. Further research on the design of nZEB's considering both network and building level is required to analyze these hypotheses.

\section{Conclusions}

The potential of using the structural thermal mass for DSM in a single family dwelling equipped with an air-to-water HP is evaluated with building energy simulations in Modelica for the heating dominated climate of Uccle (Belgium). The simulations calculate the heat demand of the building and the corresponding electricity use together with the local electricity production from a PV system. A floor heating system and low temperature radiators have been evaluated for their potential to activate the thermal mass of the building. To enable DSM, a model-based control strategy and a non-predictive strategy have been simulated and compared against a reference thermostatic control. The influence of the building structure is evaluated by analyzing 6 building cases, i.e. 3 insulation levels for both a massive and a light-weight structure.

The mismatch between the electricity demand and the PV production is illustrated. When only the domestic use is considered, an annual cover factor $(\gamma)$ of 0.31 is found, indicating that $69 \%$ of the PV production is not instantaneously balanced by the local demand. The cover factors decrease even further when the electricity use of the HP is included and the PV system is sized to cover both the domestic electricity demand and the electricity demand for heating. The strongest mismatch is found for the less insulated building equipped with a floor heating system $(\gamma=0.16)$, since the electricity use for the floor heating system is mostly concentrated in the morning when the PV production is limited. Moreover, this scenario results in the highest peak demand and peak production and is therefore expected to have a high impact on the grid stability. Therefore it could be argued that the first step in creating zero energy buildings should try to reduce the heat demand of the dwelling.

Results show that the use of the structural storage capacity in buildings is able to reduce the HP electricity use during peak demand periods significantly. The highest reductions are obtained using the non-predictive control strategy and vary between $75 \%$ and $94 \%$ for the radiator heating system and the floor heating system respectively. The floor heating system thereby shows better peak shaving potential since it is able to directly activate the thermal mass where the radiators tend to heat mostly the indoor air, resulting in faster temperature fluctuations. Moreover, the DSM potential is higher for the massive buildings compared to the lightweight buildings.

Nonetheless, it is important to note that activating the thermal mass demands for active control of the indoor temperature and is therefore limited by thermal comfort boundaries. Also, it is stressed that activating the structural thermal storage increases the total energy use. This increased energy use needs to be balanced by efficiency gains at building or network level to make DSM using the structural storage profitable from an energy point of view.

It is shown that increasing the insulation quality and implementing a model-based control strategy, that takes into account the predicted heat demand, results in a less strong increase of the total energy use. For the model-based control strategies even reductions of the total energy use are found when the decrease of the heat demand during peak demand periods, due to the reduction of the temperature setpoint, is more important than the increased demand during peak supply periods.
In contrast to the peak reductions, the influence of the DSM on the self-consumption of PV electricity is limited. The low values of the cover factors result from the seasonal mismatch between the heating demand and the PV production. Whereas DSM using the structural storage of the dwelling shows high potential for peak shifting over a time span of hours and days, long term storage is required to improve this seasonal mismatch. Nevertheless, in the context of Smart Grids where DSM is mostly required in the order of hours to days, the use of the structural thermal storage capacity in dwellings shows strong potential.

\section{References}

[1] Johansson TB, Turkenburg W. Policies for renewable energy in the European Union and its member states: an overview. Energy Sustain Dev 2012;8(1):524. http://dx.doi.org/10.1016/S0973-0826(08)60387-7.

[2] Edenhofer O, Pichs-Madruga R, Sokona Y, Seyboth K, Patrick M, Kadner S, et al. Ipcc special report on renewable energy sources and climate change mitigation. Tech. Rep. Intergovernmental Panel on Climate Change, ISBN 978-929169-131-9; 2011.

[3] Baetens R, De Coninck R, Van Roy J, Verbruggen B, Driesen J, Helsen L, et al. Assessing electrical bottlenecks at feeder level for residential net zero-energy buildings by integrated system simulation. Appl Energy 2012;96:74-83. http://dx.doi.org/10.1016/i.apenergy.2011.12.098.

[4] Lund H, Marszal A, Heiselberg P. Zero energy buildings and mismatch compensation factors. Energy and Buildings 2011;43(7):1646-54. http:/ dx.doi.org/10.1016/j.enbuild.2011.03.006

[5] Widén J, Wäckelgard E, Lund PD. Options for improving the load matching capability of distributed photovoltaics: methodology and application to highlatitude data. Solar Energy 2009;83(11):1953-66. http://dx.doi.org/10.1016 j.solener.2009.07.007

[6] Torcellini P, Pless S, Deru M, Crawley D. Zero energy buildings: a critical look at the definition preprint. In: 2006 ACEEE summer study on energy efficiency in buildings 2006. Pacific Grove, California.

[7] Marszal A, Heiselberg P, Bourrelle J, Musall E, Voss K, Sartori I, et al. Zero Energy Building A review of definitions and calculation methodologies. Energy and Buildings 2011;43(4):971-9. http://dx.doi.org/10.1016/j.enbuild.2010.12.022.

[8] Bayod-Rújula AA. Future development of the electricity systems with distributed generation. Energy 2009;34(3):377-83. http://dx.doi.org/10.1016/ j.energy.2008.12.008.

[9] Pepermans G, Driesen J, Haeseldonckx D, Belmans R, Dhaeseleer W. Distributed generation: definition, benefits and issues. Energy Policy 2005;33(6): 787-98. http://dx.doi.org/10.1016/j.enpol.2003.10.004.

[10] Lopes JP, Hatziargyriou N, Mutale J, Djapic P, Jenkins N. Integrating distributed generation into electric power systems: a review of drivers, challenges and opportunities. Electric Power Syst Res 2007;77(9):1189-203. http:/ dx.doi.org/10.1016/j.epsr.2006.08.016

[11] Battaglini A, Lilliestam J. Haas A, Patt A. Development of supersmart grids for a more efficient utilisation of electricity from renewable sources. J Clean Prod 2009;17(10):911-8. http://dx.doi.org/10.1016/j.jclepro.2009.02.006.

[12] Hammons T. Integrating renewable energy sources into European grids. Int J Electr Power Energy Syst 2008;30(8):462-75. http://dx.doi.org/10.1016 j.ijepes.2008.04.010.

[13] Hamalainen RP, Mantysaari J, Ruusunen J, Pineau PO. Cooperative consumers in a deregulated electricity market dynamic consumption strategies and price coordination. Energy 2000;25:857-75.

[14] Beaudin M, Zareipour H, Schellenberglabe A, Rosehart W. Energy storage for mitigating the variability of renewable electricity sources: an updated review. Energy Sustain Dev 2010;14(4):302-14. http://dx.doi.org/10.1016/j.esd.2010. 09.007.

[15] Ibrahim H, Ilinca A, Perr J. Energy storage systems characteristics and comparisons. Renew Sustain Energy Rev 2008;12(5):1221-50. http://dx.doi.org/ 10.1016/j.rser.2007.01.023

[16] Mulder G, Ridder FD, Six D. Electricity storage for grid-connected household dwellings with PV panels. Solar Energy 2010;84(7):1284-93. http:/ dx.doi.org/10.1016/j.solener.2010.04.005.

[17] Zahedi A. Maximizing solar PV energy penetration using energy storage technology. Renew Sustain Energy Rev 2011;15(1):866-70. http://dx.doi.org/ 10.1016/j.rser.2010.09.011.

[18] International Energy Agency. Technology roadmap energy-efficient buildings: heating and cooling equipment. Tech. Rep 2011.

[19] Xing Y, Hewitt N, Griffiths P. Zero carbon buildings refurbishment: a hierarchical pathway. Renew Sustain Energy Rev 2011;15(6):3229-36. http:// dx.doi.org/10.1016/j.rser.2011.04.020.

[20] Qureshi Wa, Nair NKC, Farid MM. Impact of energy storage in buildings on electricity demand side management. Energy Convers Manag 2011;52(5): 2110-20.. http://dx.doi.org/10.1016/j.enconman.2010.12.008.

[21] Oldewurtel F, Parisio A, Jones CN, Gyalistras D, Gwerder M, Stauch V, et al. Use of model predictive control and weather forecasts for energy efficient building climate control. Energy and Buildings 2012;45:15-27. http://dx.doi.org 10.1016/j.enbuild.2011.09.022. 
[22] Henze GP, Felsmann C, Knabe G. Evaluation of optimal control for active and passive building thermal storage. Int J Therm Sci 2004;43(2):173-83. http:/I dx.doi.org/10.1016/j.ijthermalsci.2003.06.001.

[23] Braun J, Montgomery K, Chaturvedi N. Evaluating the performance of building thermal mass control strategies. HVAC\&R Res 2001;7(4):403-28.

[24] Kintner-Meyer M, Emery A. Optimal control of an HVAC system using cold storage and building thermal capacitance. Energy and Buildings 1995;23(1): 19-31. http://dx.doi.org/10.1016/0378-7788(95)00917-M.

[25] Kummert M, André P, Nicolas J. Optimal heating control in a passive solar commercial building. Solar Energy 2001;69:103-16. http://dx.doi.org/ 10.1016/S0038-092X(01)00038-X.

[26] Castilla M, ÁlvarezJ, Berenguel M, Rodríguez F, Guzmán J, Pérez M. A comparison of thermal comfort predictive control strategies. Energy and Buildings 2011;43(10):2737-46. http://dx.doi.org/10.1016/j.enbuild.2011.06.030.

[27] Mozer M, Vidmar L, Dodier R. The neurothermostat: predictive optimal control of residential heating systems. In: Advances in neural information processing system 9. Cambridge, MA: MIT Press; 1997. 10.1.1.49.2620.

[28] Fanger P. Thermal comfort: analysis and applications in environmental engineering. United States: McGraw-Hill Book Company; 1970

[29] ISO 7730. Ergonomics of the thermal environment analytical determination and interpretation of thermal comfort using the PMV and PPD indices and local thermal comfort criteria 2005.

[30] Nicol JF, Humphreys MA. Adaptive thermal comfort and sustainable thermal standards for buildings. Energy and Buildings 2002;34:563-72.

[31] Peeters L, Van der Veken J, Hens H, Helsen L, Dhaeseleer W. Control of heating systems in residential buildings: current practice. Energy and Buildings 2008;40(8):1446-55. http://dx.doi.org/10.1016/j.enbuild.2008.02.016.

[32] de Dear R, Brager G. Towards an adaptive model of thermal comfort and preference. ASHRAE Trans 1998;104(1):145-67.

[33] Roth K, Dieckmann J, Brodrick J. Using off-peak precooling. ASHRAE J 2009: 80-3. March.

[34] Braun JE. Load control using building thermal mass. J Solar Energy Eng 2003;125(3):292-301. http://dx.doi.org/10.1115/1.1592184.

[35] Liu S, Henze GP. Experimental analysis of simulated reinforcement learning control for active and passive building thermal storage inventory. Energy and Buildings 2006;38(2):142-7. http://dx.doi.org/10.1016/j.enbuild.2005.06.002.

[36] Balaras C. The role of thermal mass on the cooling load of buildings. An overview of computational methods. Energy and Buildings 1996;24(1):1-10. http://dx.doi.org/10.1016/0378-7788(95)00956-6.
[37] Holford JM, Woods AW. On the thermal buffering of naturally ventilated buildings through internal thermal mass. J Fluid Mech 2007;580:3-29. http:// dx.doi.org/10.1017/S0022112007005320.

[38] Rijksen D, Wisse C, van Schijndel A. Reducing peak requirements for cooling by using thermally activated building systems. Energy and Buildings 2010;42(3):298-304. http://dx.doi.org/10.1016/j.enbuild.2009.09.007.

[39] Corgnati SP, Kindinis A. Thermal mass activation by hollow core slab coupled with night ventilation to reduce summer cooling loads. Building Environ 2007;42(9):3285-97. http://dx.doi.org/10.1016/j.buildenv.2006.08.018.

[40] Russell M, Surendran P. Influence of active heat sinks on fabric thermal storage in building mass. Appl Energy 2001;70(1):17-33. http://dx.doi.org/ 10.1016/S0306-2619(01)00023-X.

[41] Wang Z, Yi L, Gao F. Night ventilation control strategies in office buildings. Solar Energy 2009;83(10):1902-13. http://dx.doi.org/10.1016/j.solener.2009. 07.003.

[42] Verbeeck G. Optimisation of extremely low energy residential buildings. phd-thesis. K.U.Leuven; 2007.

[43] BIN. NBN D50-001:1991-Ventilation systems for housing (Dutch). Tech. Rep 1991.

[44] Verbruggen B, Van Roy J, De Coninck R, Baetens R, Helsen L, Driesen J. Objectoriented electrical grid and photovoltaic system modelling in Modelica. In: 8th Int. Modelica Conf. March 20-22, Dresden; 2011.

[45] Meteotest. METEONORM version 6.1-edition 20092008

[46] CEN. EN 12831 Heating systems in buildings - method for calculation of the design heat load 2003.

[47] CEN. EN 442-2:1996 Radiators and convectors - Part 2: test methods and rating 1996.

[48] CEN. EN 15377-2 Heating systems in buildings - design of embedded water based surface heating and cooling systems - Part 2: design, dimensioning and installation 2008

[49] Koschenz, Lehmann. Thermoaktive Bauteilsysteme tabs. Duebendorf (Switzerland): EMPA Energiesysteme/Haustechnik; 2000.

[50] Hast A. Annex 10 system simulation, thermostatic valve 1988.

[51] CEN. Standard EN ISO 13790: energy performance of buildings calculation of energy use for space heating and cooling 2008

[52] Baetens R, De Coninck R, Helsen L, Saelens D. The impact of the heat emission system on the grid-interaction of building integrated photovoltaics in lowenergy dwellings. In: 8th international conference on system simulation in buildings, vol. 1. Liège: SSB 2010; 2010. p. 1-13. 